von welchen ein wenig mehr als $2 / 3$, nämlich 9,5 C.C., aus Kohlensäure bestanden. Eine kleine Menge flüssiger Kohlenwasserstoff fărbte das verdichtete Wasser.)

Wasser und Weingeist auf den pompejanischen Weizen sowohl kalt als warm einwirkend, färbten sich leicht brïunlich und die Auszüge gaben in Wasserbade verdunstet kleine Mengen stickstoffhaltiger Rückstände.

Aether und Schwefelkohlenstoff entzogen diesem Weizen fast nichts.

Die mikroskopische Untersuchung zeigte in dem poinpejanischen Weizen keine organisirte Substanz, welche durch Jod sich färbte; dieselbe enthielt eben so wenig Stoffe, die das weinsaure Kupferoxyd-Kali reducirten, noch Stoffe, die mit Bierhefe in Gährung kamen.

Die Oberhaut war matt, glatt und liess sich leicht von den inneren Parthien des Kornes trennen, welche noch bestimmt die zellige Structur des normalen Korns zeigten.

Die Menge des Stickstoffs im pompejanischen Weizen entspricht genau derjenigen, welche man im gewöhnlichen Weizen tindet; dies verdient hervorgehoben $\mathrm{zu}$ werden, denn nach 1800jühriger Aufbewahrung, nachdem dieser Weizen Wasserstoff und fast allen Sauerstoff verloren hatte, behielt er vielleicht seinen ganzen Kohlenstoff- und sicher seinen Gesammtstickstoffgehalt. Diese Umwandlung ist nicht einer Veränderung durch hohe Temperatur, als vielmehr der langen Einwirkung der atmosphärischen Agentien zuzuschreiben.

Der Weizen von Pompeji, obgleich er seine ursprüngliche Form beibehalten, hat jede Spur organischer Producte verloren und enthält weder Kleber, noch Stärkemehl, weder Zucker, noch fette Substanzen; er hat sich in der Art zersetzt, dass man in ihm noch allen Stickstoff und beinahe allen Kohlenstoff des gewöhnlichen Weizens findet; aber die Mineralbestandtheile, welche in grosser Menge darin vorkommen, sind theilweise aus dem Wasser in die Körner gelangt, welches die durchdringliche, amorphe kohlige Masse der humificirten Körner durch die Jahrhunderte hindurch benetzte. (Compt. rend. 7. Sept. 1863. p. 500.)

H. Ludwig.

\title{
Glycerin gegen Taubheit
}

hat sich in zwei Fällen höchst wirksam erwiesen : bei einem seit 18 Jahren tauben Manne von 37 Jahren 
und einer seit 30 Jahren tauben Frau von 55 Jahren. In beiden Fällen war das Trommelfell verdickt, ohne Spur einer Secretion. Das Glycerin wurde durch einen dannit befeuchteten Pinsel eingeführt und bewirkte im ersten Falle völlige Heilung; im zweiten Falle trat wieder Taubheit ein, weil die Anwendung vernachlässigt wurde. (Journ. de Pharm. d'Anvers. Juin 1863.) Dr. Keich.

\section{Explosives Glycerin (Pyroglyeerin).}

Dasselbe stellt man nach Sobrero her, wenn man 2 Vol. Schwefelsäure von $66^{\circ}$ und 1 Vol. Salpetersäure von $40^{\circ}$ mischt und nach dem Erkalten ungefähr den 6ten Theil vom Volumen der ganzen Flïssigkeit Glycerin hinzufügt. Dieses löst sich sofort, bald aber trübt sich die Flüssigkeit und ein gelbliches klares Oel sammelt sich an der Oberfläche. Man wäscht mit dem 15-20 fachen Vol. kalten Wassers und fährt damit so lange fort, bis das abfliessende Wasser frei von Säure ist. Schliesslich trocknet man unter der Luftpumpe.

Das Pyroglycerin hat ein spec. Gew. von 1,60 , ist geruchlos und schwach gelb gefärbt. Es hat einen süsslichen angenehmen Geschmack, ist aber giftig. wie man durch Versuche an Thieren festgestellt hat. Auf Papier macht es einen Oelfleck, es ist noch bei $20^{\prime}$ tlüssig, unlöslich in Wasser, sehr löslich in Alkohol und Aether, es ist nicht flüchtig und verträgt eine Temperatur von 1000 . Ein Tropfen dieses Glycerins langsam auf Platinblech erhitzt, zersetzt sich unter Entwickelung salpetriger Dämpfe. Bei höherer Temperatur tritt die Zersetzung plötzlich unter Verpuffung und Entzündung ein. Es bleibt dann wenig Kohle zurïck. Wenn man eine kleine Menge von Pyroglycerin sehr schnell erhitzt, so erfolgt eine heftige Detonation. Ein Tropfen von einigen Decigrammen verunag einen Knall wie ein Pistolenschuss zu geben. Trocknes Pyroglycerin detonirt auch beim Schlagen. (Journ.de (him. méd. - Ghem. Ventrbl. 1863 28.)

$B$.

\section{Sulfhydrate des Glycerins.}

Durch Umsotzung des Mono-, Di- und Tri-Chlorhydrins mit Kaliumsulfhydrat stellte L. Carius die dem Glycerin entsprechenden Sulfhydrate dar. Fs sind dies 